\title{
Disintegration and Recycling of Multi-layered Glass Fiber Reinforced Polymer Composites via Superheated Steam
}

\author{
Chi Hoong Chan ${ }^{1}$, Minato Wakisaka ${ }^{1}$ and Haruo Nishida ${ }^{1,}$ a \\ ${ }^{1}$ Graduate School of Life Science and Systems Engineering, Kyushu Institute of Technology, 2-4 Hibikino, Wakamatsu-ku, Kitakyushu, 808- \\ 0196 Fukuoka, Japan.
}

\begin{abstract}
To increase viability of recycling of robust and large-scale multi-layered glass fiber reinforced polymer composites (GFRPs), disintegration of the multi-layered GFRPs and recovery of fibers/resin-derived materials were investigated using superheated steam (SHS) under normal pressure where a very quick heat transfer to GFRP was possible. The SHS treatment of 4 different types of multi-layered GFRP products were conducted at $350{ }^{\circ} \mathrm{C}$ in an oxygen-free environment up to 3 hours. The SHS treated GFRPs were easily disintegrated into each layer. The separated layers were divided into components: glass fibers, oligomers, and inorganic fillers after subsequent thermal and ultrasonication processes. Finally, clear glass fibers were recovered, and matrix resin was also recovered as soluble oligomers consisting of phthalates, glycols, and styrene units due to partial chain cleavage of cured resin. These results clearly showed the viability for the recycling of actual large-scale multi-layered GFRP products.
\end{abstract}

\section{Introduction}

Thermosetting polymers have been proved to be more suited in applications for harsher environments because of their three-dimensional network structures that made the material stronger, more stable at high temperature, and more resistant towards chemical stimulations compared to thermoplastics. In addition, by adding high strength fibers to thermosets, high-performance fiberreinforced polymer composites (FRPs) can be obtained. Various high-strength / high-modulus fibers such as aramid fibers, carbon fibers, glass fibers, etc. have been used extensively to reinforce thermosets [1]. The composites are tougher, more durable and lighter in weight compared to traditional materials like steel [2]. These benefits are contributable to higher ease in handling and longer service life of products. Therefore, FRPs have been using extensively in various industries such as civil engineering [3], aerospace [4], marine [5], and automotive $[6,7]$.

However, the durability of FRPs has been called into questions as they are nearing their expected service life, due to their lack of a proper life-cycle assessment [2]. Conventional thermoset FRPs cannot enter reprocessing or recycling systems which consist of various raw materials including, fibers, sizing agents, fillers, and other additives, making their recycling very difficult. For this reason, FRPs such as glass fiber reinforced polymer composite (GFRP) have been usually disposed via landfilling or incineration [8]. In Japan, the waste disposal using land filling method is secondary compared to incineration as the primary mode of disposal [9]. The incineration of wastes allows the energy recovery from their organic components. However, incombustible materials from the incineration process are usually collected, treated, and finally disposed by land-filling. Therefore, secondary usage of FRP-derived materials should be encouraged.

FRP-recycling mainly focused on recovering the more expensive reinforcing fibers, e.g. pyrolysis [10], with oxide semiconductors [11] and subcritical fluids [12], while little attention has been paid to polymer components to recover, for example, a styrene-fumaric acid copolymer $[13,14]$. A recent review by Oliveux et al. classified the FRP recycling into 3 different modes, namely, mechanical, thermal, and solvolysis [15]. Solvolysis method that increases the economic viability of FRP recycling by allowing the total recovery of fibers and polymers has been demonstrated. Recently, hydrothermal treatment with steam of GFRP has been investigating without using any chemical agents. Shi and Bao reported the superheated steam (SHS) degradation of a cured unsaturated polyester (UP) and the single layered GFRP prepared by hand lay-up molding. The GFRP was treated by SHS at $340-450{ }^{\circ} \mathrm{C}$ to remove resins and recover glass fibers with char attached [16]. Nishida et al. also treated the single-layered GFRP with a gel-coated surface layer by SHS at $300{ }^{\circ} \mathrm{C}$ to remove resins and recover glass fibers [17]. Despite the many previous studies, there are a few reports [18] published regarding the recycling of actual multi-layered GFRP products, which have been used as large-scale structures for buildings and civil engineering constructions. In this study, the disintegration viability of multi-layered GFRP

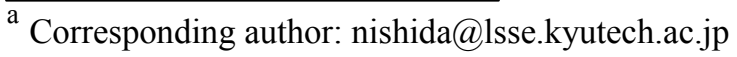


was investigated to facilitate the recovery of glass fibers and organic components from the robust multi-layered GFRPs using SHS under normal pressure. Four types of robust GFRP products with different layered structures were used in SHS treatments. As results, the GFRPs were successively separated to each layer while hydrolyzed oligomers were also extracted. With subsequent thermal degradations, clear glass fibers were also recovered.

\section{Materials and Methods}

\subsection{Materials}

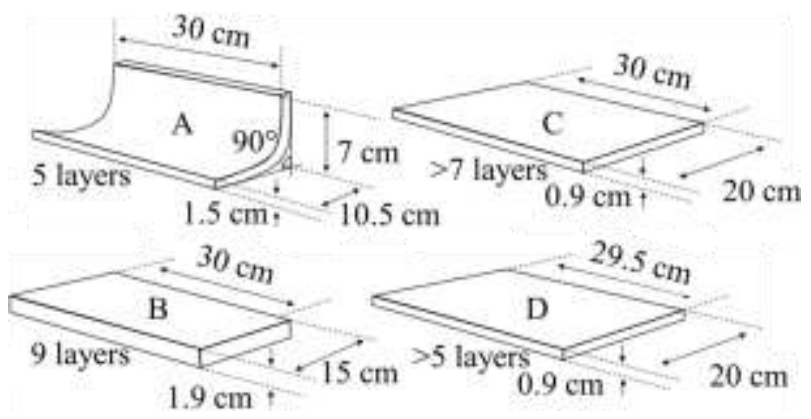

Fig. 1 Dimensions and layer structures of GFRP samples.

Four different types of multi-layered GFRPs with various dimensions, shapes, and layer structures, which were listed in Table 1 and Fig. 1, a typical unsaturated polyester (UP, poly (phthalic acids-fumaric acid-glycols) including styrene monomer of $32.8 \mathrm{wt} \%$ ), and initiator: methyl ethyl ketone peroxide (MEKP) were provided from Kurimoto, Ltd. (Osaka, Japan). Five kinds of solvents: chloroform, n-hexane, acetone, toluene, and methyl alcohol were purchased from Wako Pure Chemical Industries, Ltd. and used as received.

\subsection{Methods}

\subsubsection{Curing of Unsaturated Polyester}

Unsaturated polyester (UP) was cured by polymerization of styrene using MEKP at $1.0 \mathrm{vol} \%$ according to the preparative procedure recommended by the producer. The UP including MEKP was stirred at $25^{\circ} \mathrm{C}$ for $24 \mathrm{~h}$, followed by heating at $70{ }^{\circ} \mathrm{C}$ for $3 \mathrm{~h}$, resulting in hardening of UP to cured resin.

\subsubsection{SHS and Thermal Treatments Procedures}

The multi-layered GFRPs (Table 1 and Fig. 1) and UP were treated by SHS in a SHS oven QF-5200C (Naomoto Corp., Osaka, Japan) at $350{ }^{\circ} \mathrm{C}$ for 1 or $3 \mathrm{~h}$. After the SHS treatment, GFRPs were immediately cooled to ambient temperature using a fan and weighed. The SHStreated samples were easily disintegrated to each layer even by handwork. Mechanically separated layers were then subjected to thermal treatment in a pre-heated furnace MMF-1 (AS ONE Corporation, Osaka, Japan) at $500{ }^{\circ} \mathrm{C}$ for $1 \mathrm{~h}$ under atmospheric conditions. The heat-
Table 1. Multi-layered GFRPs.

\begin{tabular}{cccl}
\hline Samp. & $\begin{array}{c}\text { Thickn. } \\
(\mathrm{mm})\end{array}$ & Number & \multicolumn{1}{c}{ Components } \\
\cline { 3 - 4 } A & 15 & 5 & $\begin{array}{l}\text { glass fiber inner core layer; } \\
\text { strands; and outermost mat } \\
\text { layers at both sides }\end{array}$ \\
\hline B & 19 & 9 & $\begin{array}{l}\text { mortar inner core (silica); } \\
\text { glass fiber, 3-layers mats; } \\
\text { and outermost single layer } \\
\text { are with fillers }\end{array}$ \\
\hline C & 9 & $>7$ & $\begin{array}{l}\text { mortar inner core (silica); } \\
\text { glass fiber, mat layer; and } \\
\text { outermost intercalated 2- } \\
\text { layers }\end{array}$ \\
\hline & & & $\begin{array}{l}\text { mortar inner core (silica) } \\
\text { layer; glass fiber, 2-layers } \\
\text { mats; outermost layer with } \\
\text { chopped glass fibers }\end{array}$ \\
\hline
\end{tabular}

treated sample layers were then allowed to cool down before subjecting to ultrasonication in an US-103 (Sansyo Co., Ltd., Tokyo, Japan) to remove attached organic materials. Finally, glass fibers were recovered after ovendrying at $105{ }^{\circ} \mathrm{C}$ for $24 \mathrm{~h}$. For comparison sake, GFRP sample $\mathrm{A}$ in Table 1 was also heat-treated at $350{ }^{\circ} \mathrm{C}$ for $3 \mathrm{~h}$ without steam under atmospheric conditions. After the heat-treatment, sample A was immediately cooled to ambient temperature using a fan and weighed.

\subsection{Characterizations}

Chemical structures of GFRP samples were analyzed with a Fourier transform infra-red (FT-IR) spectrometer (Nicolet iZ10, ThermoScientific, Waltham, MA, USA) via a transmission mode using $\mathrm{KBr}$ pellet. The spectrum was recorded in a wavenumber range of 400 to $4000 \mathrm{~cm}^{-1}$ with spectral resolution of $4 \mathrm{~cm}^{-1}$ and 16 scans per sample. The surface morphologies of SHS treated GFRPs were observed under a 3D laser scanning confocal microscope (LSCM) model VK-X 100/105 (KEYENCE Corporation, Osaka, Japan) under prescribed conditions of laser: red semiconductor laser, $\lambda=658 \mathrm{~nm}, 0.95 \mathrm{~mW}$, and pulse width of $1 \mathrm{~ns}$ using a depth composition procedure to check the presence of residual materials and quality of glass fiber surfaces. Proton $\left({ }^{1} \mathrm{H}\right)$ nuclear magnetic resonance (NMR) spectra of chloroform-extracted materials from SHS-treated GFRPs were recorded on a $500 \mathrm{MHz}$ JNM-ECP 500 FT-NMR system (JEOL Ltd., Tokyo, Japan). Tetrachloroethane-d2 (TCE-d2) was used as a solvent. Size-exclusion chromatography (SEC) measurements of chloroform-extracted materials from SHS-treated GFRPs were analysed using TOSOH HLC8320 GPC system (Tosoh Corporation, Tokyo, Japan) with refractive index (RI) and ultra-violet (UV) detectors at $40{ }^{\circ} \mathrm{C}$ using TOSOH TSK Gel Super HM-M column (linearity range: $1 \times 10^{3}-8 \times 10^{6}$; molecular weight (MW) exclusion limit $\left.4 \times 10^{8}\right)$ and a chloroform eluent $(0.6$ $\mathrm{mL} / \mathrm{min}$ ). Calibration curves for SEC analysis were obtained using polystyrene standards with low polydispersity and number-average molecular weight $(\mathrm{Mn})$ of $5.89 \times 10^{2}, 1.01 \times 10^{3}, 2.5 \times 10^{3}, 5.43 \times 10^{3}, 9.49$ 
$\times 10^{3}, 1.37 \times 10^{4}, 3.72 \times 10^{4}, 9.89 \times 10^{4}, 1.89 \times 10^{5}, 3.97$ $\times 10^{5}, 7.07 \times 10^{5}$, and $1.11 \times 10^{6}$. Approximately $10 \mathrm{mg}$ of sample was dissolved in $2 \mathrm{~mL}$ chloroform, stirred for 2 $\mathrm{h}$ at room temperature, and filtered through a membrane filter with $0.45 \mu \mathrm{m}$ pore size to be suitable for use in the SEC analysis.

\section{Results and Dlscussions}

\subsection{Morphological and Weight Changes after SHS and After Thermal Treatment}

To disintegrate the multi-layered GFRP samples and recover clear glass fibers, SHS-treatment at $350{ }^{\circ} \mathrm{C}$ for $3 \mathrm{~h}$, thermal degradation at $500{ }^{\circ} \mathrm{C}$ for $1 \mathrm{~h}$, and subsequent ultrasonication were conducted. Weight loss values during the successive treatments were listed in Table 2. After $3 \mathrm{~h}$ of treatment, all GFRP samples decreased in weight by 13.2-25.8 \%, and easily disintegrated into each layer even by handwork (Fig. 2). After $1 \mathrm{~h}$ of the SHS treatment, the GFRP samples were disintegrable by weak mechanical stress. Robust multilayered GFRPs of 9-19 mm in thickness (Table 1), can be penetrated by SHS at $350{ }^{\circ} \mathrm{C}$ from outermost layers of GFRPs and diffuse into inner core layers to disintegrate the layer structures. As a comparison, s imple heat treatment of GFRP sample A was also conducted in the same oven at $350{ }^{\circ} \mathrm{C}$ for $3 \mathrm{~h}$ without SHS. After the heat treatment, sample A partially changed color into pale brown and decreased weight by $3.24 \%$ but did not disintegrate. Other GFRP samples showed the same changes. These results clearly show the significant effect of SHS treatment to disintegrate the robust multi-layered GFRP products.

The SHS-treated GFRP samples were subjected to subsequent thermal degradation at $500{ }^{\circ} \mathrm{C}$ for $1 \mathrm{~h}$ with each layer. After the thermal degradation, the layers showed additional weight loss by $2.1-24.7 \%$, varying dependent on layer components. Particularly, the outermost layers showed the highest weight loss, indicating that the outermost layers have the highest number of organic components, which remained even after the SHS treatment. While the inner core layers showed the lowest weight loss, because the layers are consisted of a large amount of fillers such as $\mathrm{SiO}_{2}$. As shown in Fig. 2, GFRP samples and separated layers after $3 \mathrm{~h}$ of SHS treatment changed color from light gray to brown / dark gray, which was attributed to the steamdegraded resin (SDR) derived from cured UP. Some layers clearly showed embedded glass fibers (Fig. 2) and the inner core layers showed fragmentation of mortar layer.

The thermally treated layers were subsequently subjected to ultrasonication to separate the remaining SDR on glass fiber surfaces in distilled water, resulting in clean glass fibers and recovery of powdery $\mathrm{SiO}_{2}$ fillers from outer layers and inner mortar core layers (Fig. 3). Although the thermal and ultrasonication treatments were used to achieve the recovery of clear fibers, it was also

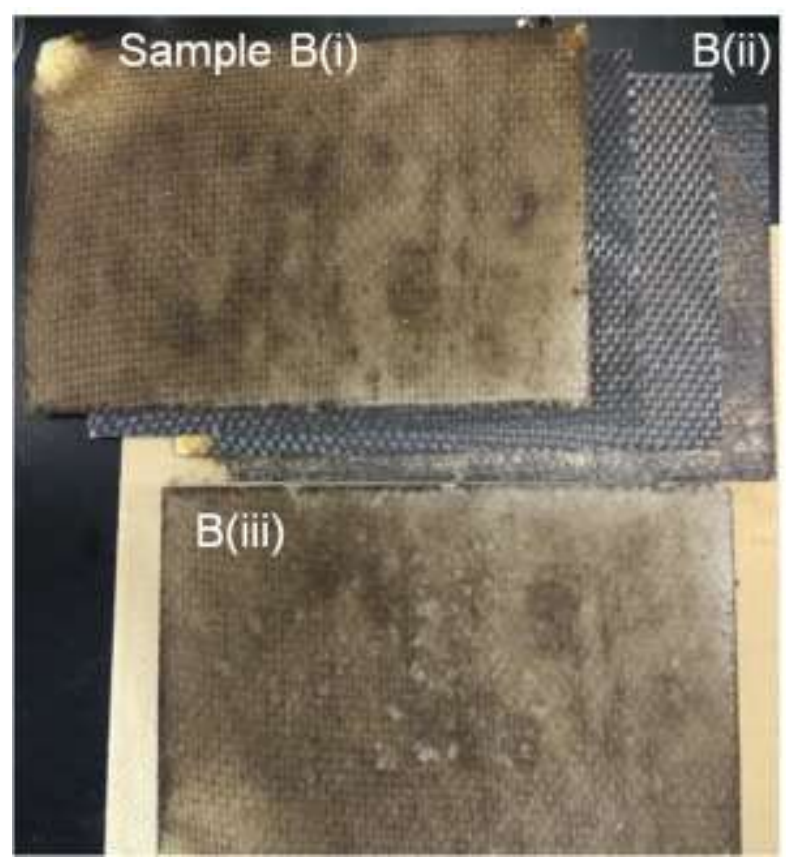

Figure 2. Separated GFRP sample layers after SHS treatment at $350{ }^{\circ} \mathrm{C}$ for 3 h. (a) sample B: (i) outermost, (ii) multiple glass fiber mats and (iii) mortar core layers.

Table 2 Weight loss values of multi-layered GFRPs after SHS and thermal treatments

\begin{tabular}{|c|c|c|c|c|}
\hline \multirow{2}{*}{ Samp. } & \multirow{2}{*}{$\begin{array}{c}\text { Initial } \\
\text { Mass } \\
(\mathrm{kg})\end{array}$} & \multirow{2}{*}{$\begin{array}{c}\text { SHS } \\
\left(\begin{array}{c}\text { wt.\%) } \\
\mathrm{a}\end{array}\right.\end{array}$} & \multicolumn{2}{|c|}{ Thermal Treatment ${ }^{\mathrm{b}}$} \\
\hline & & & Separated Components & $(\mathrm{wt} \%)$ \\
\hline \multirow{3}{*}{ A } & \multirow{3}{*}{1.32} & \multirow{3}{*}{25.8} & outermost layers & 24.7 \\
\hline & & & glass fiber strand layers & 11.6 \\
\hline & & & glass fiber inner core & 8.3 \\
\hline \multirow{3}{*}{ B } & \multirow{3}{*}{2.42} & \multirow{3}{*}{13.2} & outermost layers & 4.5 \\
\hline & & & glass fiber mat layers & 3.6 \\
\hline & & & mortar-based inner core & 3.1 \\
\hline \multirow{3}{*}{$\mathrm{C}$} & \multirow{3}{*}{2.52} & \multirow{3}{*}{15.9} & outermost layers & 15.8 \\
\hline & & & glass fiber strand layers & 11.3 \\
\hline & & & mortar-based inner core & 5.5 \\
\hline \multirow{2}{*}{ D } & \multirow{2}{*}{1.28} & \multirow{2}{*}{15.6} & outermost layers & 5.2 \\
\hline & & & mortar-based inner core & 2.1 \\
\hline
\end{tabular}

${ }^{a}$ SHS treatment at $350{ }^{\circ} \mathrm{C}$ for $3 \mathrm{~h}$

${ }^{\mathrm{b}}$ Thermal treatment in a furnace at $500^{\circ} \mathrm{C}$ for $1 \mathrm{~h}$

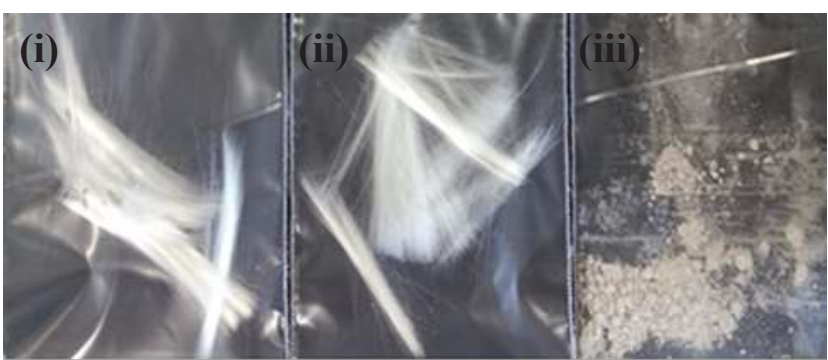

Figure 3. Glass fibers and mortar recovered from GFRP sample $\mathrm{C}$ after thermal treatment at $500{ }^{\circ} \mathrm{C}$ for $1 \mathrm{~h}$ (i) Outermost, (ii) glass fiber mat, and (iii) mortar core origins.

confirmed that these post-treatments were not necessarily needed for the recycling. It was found that other simpler methods such as vibration on a screen were also usable for separating SDR attached on the fiber surfaces. Morphologies of the recovered fibers and chemical structures of SDRs were analyzed respectively. 


\subsection{Laser Scanning Confocal Microscopy}

SHS treated GFRP samples and its subsequent thermal and ultrasonication treatments were observed under LSCM using a depth composition procedure by stitching images together at different focal length and magnification. As shown in Fig. 4 (a-d), glass fibers were clearly seen on the surfaces of the disintegrated layers by SHS treatment for $3 \mathrm{~h}$. The matrix polymer suffered noticeable degradation during the SHS treatment. Although the outlines of glass fibers were visible for all the samples, brown and black-colored SDR particulates were also observed attached on fiber surfaces. After the subsequent thermal treatment at $500{ }^{\circ} \mathrm{C}$ for $1 \mathrm{~h}$, all the samples turned white in color from the white particulates on fiber surfaces, which were determined from FT-IR analysis to be calcium carbonate $\left(\mathrm{CaCO}_{3}\right)$ filler. After the ultrasonication and washing, the white particulates were completely removed. Finally, clear glass fibers without any accretions were recovered as shown in Fig. 4(iii). During the SHS treatment, the degradation of GFRPs must start by steam penetration from outermost layers then diffuse to the inner layers, resulting in successful disintegration into each layer. However, due to the thickness and firm networks of layered glass fibers, generated SDRs were trapped inside the composite layers without being carried away by steam flow.

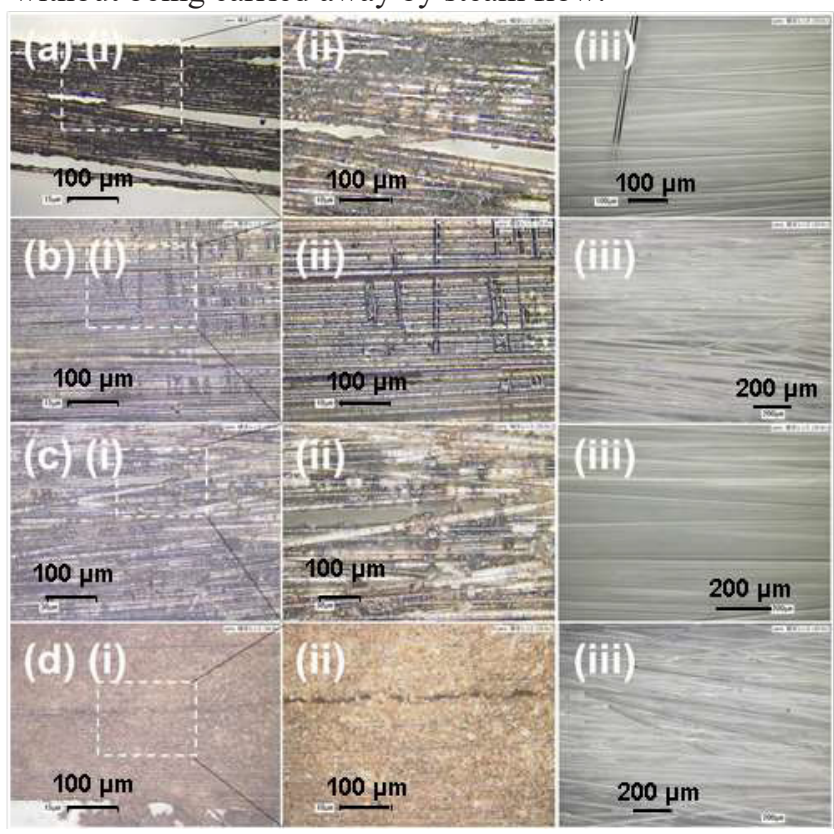

Figure 4. LSCM images of GFRP samples after SHS treatment at $350{ }^{\circ} \mathrm{C}$ for $3 \mathrm{~h}$, and their enlarged view (a)(i) sample A, (b)(i) sample B, (c)(i) sample C, (d)(i) sample D, in which (ii) enlarged samples and (iii) after thermal treatment respectively.

\subsection{FT-IR}

After the SHS treatment, SDRs were recovered from the separated layers. However, each layer consists of a distinct composition of raw materials, showing different decomposition behaviors. Cured UP without glass fiber was used as a control. From FT-IR spectra shown in Fig. 5, all samples showed the characteristic triple-peaks varomatic $\mathrm{C}-\mathrm{H}$ at 3083,3060 and $3030 \mathrm{~cm}^{-1}$ and

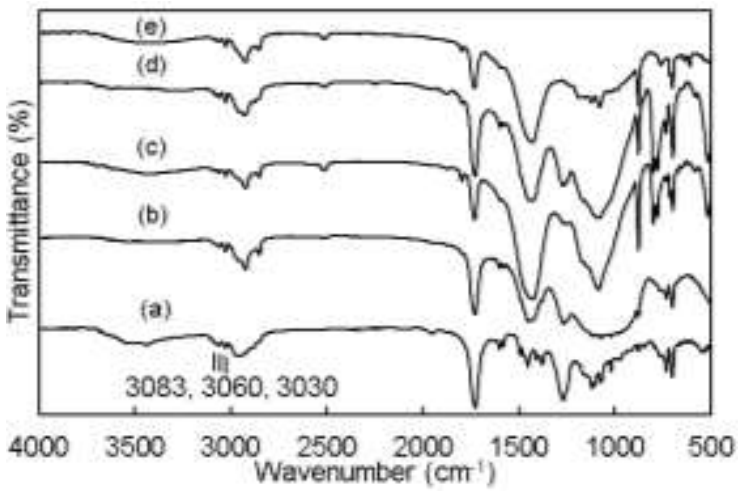

Figure 5. FT-IR spectra of (a) UP after curing and pristine GFRPs: (b) sample A, (c) B, (d) C and (e) D

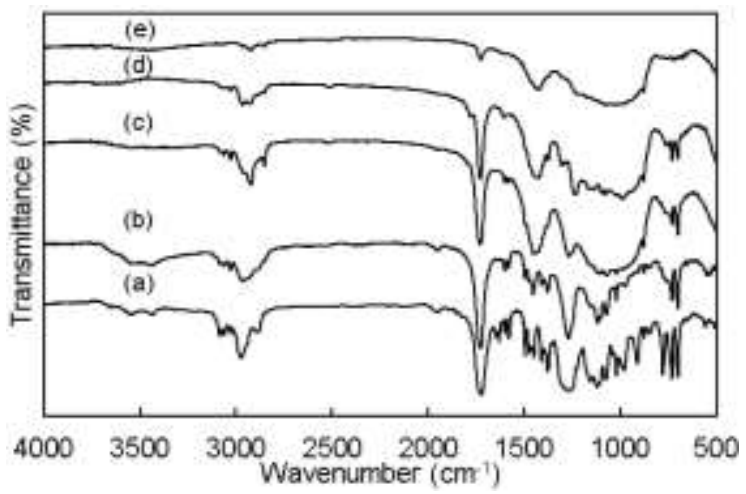

Figure 6. Changes in FT-IR spectrum of UP and GFRP (sample A) in during treatments, (a) pristine UP, (b) cured UP at $70^{\circ} \mathrm{C}$ for $3 \mathrm{~h}$, (c) sample A, and after (d) $1 \mathrm{~h}$, (e) $3 \mathrm{~h}$ of SHS treatment at $350{ }^{\circ} \mathrm{C}$, and (f) thermal decomposition at $500{ }^{\circ} \mathrm{C}$ for $1 \mathrm{~h}$ and ultrasonication

Saromatic C-H, out-of-plane at $700 \mathrm{~cm}^{-1}$. Other characteristic peaks $v \mathrm{C}=\mathrm{O}$ and $v \mathrm{C}-\mathrm{O}$ of ester groups were also found at 1730 and $1200-1300 \mathrm{~cm}-1$. Whereas, $v C=C$ peak at $1630 \mathrm{~cm}^{-1}$ derived from styrene monomer cannot be found in all spectra, indicating that all polymer matrices were cured completely.

Sample A was chosen as a representative GFRP sample to show changes in FT-IR spectrum with successive treatments, i.e., SHS treatment, thermal treatment, and ultrasonication were shown in Fig. 6. The characteristic triple-peaks varomatic $\mathrm{C}-\mathrm{H}$ were found in cured UPs, pristine and SHS $(1 \mathrm{~h})$ treated GFRPs as shown in Fig. 6(a-d). After $3 \mathrm{~h}$ of SHS treatment, the characteristic peaks almost disappeared except for $\mathrm{vC}=\mathrm{O}$ at $1730 \mathrm{~cm}^{-1}$ of ester groups (Fig. 6(e)). However, the $\nu \mathrm{C}=\mathrm{O}$ peak was not detected after the thermal treatment and ultrasonication (Fig. 6(f)). It has been reported that characteristic peaks $\mathrm{vC}-\mathrm{O}$ of aryl esters are identified to be in the range of 1210-1290 cm-1 [21]. The maximum absorption peak of $v \mathrm{C}-\mathrm{O}$ was found at $1200-1300 \mathrm{~cm}^{-1}$, which was also observed in pristine UP and all GFRPs as derived from tere/iso/ortho-phthalates (Fig. 5). The intensity of $v \mathrm{C}-\mathrm{O}$ peak diminished and subsequently disappeared after the thermal treatment and ultrasonication (Fig. 6(f)). Finally, a simple FT-IR spectrum was obtained, one broad peak and multiple peaks in ranges of $830-1350$ and $400-520 \mathrm{~cm}^{-1}$ for $v \mathrm{Si}-\mathrm{O}-$ $\mathrm{Si}$ asymmetric and $v \mathrm{Si}-\mathrm{O}-\mathrm{Si}$,symmetric, respectively, mostly derived from the glass fiber. Based on the results of FT-IR analysis matrix resin, it was clearly observed 
that SHS at $350{ }^{\circ} \mathrm{C}$ effectively degraded the cured UP by cleaving not only ester bonds, but also C-C bonds as observed as diminishing in many characteristic peaks, and SDR was completely removed by the subsequent thermal treatment and ultrasonication. Finally, the clear glass fibers were recovered.

\subsection{Analysis of SDR ( ${ }^{1} \mathrm{H}-\mathrm{NMR}$ and SEC)}

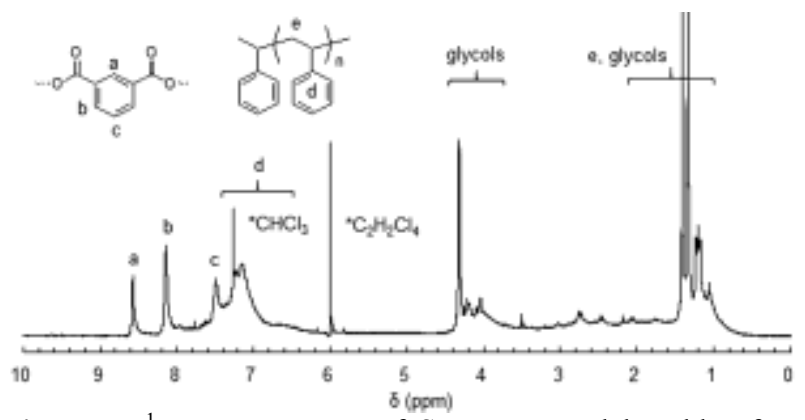

Figure 7. ${ }^{1} \mathrm{H}-\mathrm{NMR}$ spectra of SDR extracted by chloroform from sample A after $1 \mathrm{~h}$ of SHS treatment at $350{ }^{\circ} \mathrm{C}$

Previously, the hydrolytic degradation of cured UP has been conducted via subcritical water at $230{ }^{\circ} \mathrm{C}$ and 2.8 $\mathrm{MPa}$ with $\mathrm{NaOH}$ or $\mathrm{KOH}$, resulting in recovery of styrene-fumaric acid copolymers [13]. In this study, milder and more feasible SHS conditions: $350{ }^{\circ} \mathrm{C}$ under normal pressure were selected to recycle large scale products. After the SHS treatment for $1 \mathrm{~h}$, SDR from GFRP sample A was extracted by chloroform and analyzed with $1 \mathrm{H}-\mathrm{NMR}$ using TCE-d 2 as a solvent. Fig. 7 shows the 1H-NMR spectrum of SDR extracted by $\mathrm{CHCl}_{3}$. Main components of SDR were identified as a mixture of isophthalate, glycols, and styrene moieties detected in chemical shift ranges of 7.5-8.7, 3.5-4.5 / 0.61.5, and 6.2-7.4 / 1.0-2.0 ppm, respectively.

The SDR extracted from GFRP sample A from the same sample in Fi.g 7, was a low molecular weight oligomer. Number-average $\left(\mathrm{M}_{\mathrm{n}}\right)$ and weight-average molecular weight $\left(\mathrm{M}_{\mathrm{w}}\right)$ values of $1.2 \times 10^{3}$ and $5.7 \times 10^{3}$, were obtained using RI detector. When used UV detector, $M_{n}$ and $M_{w}$ values were estimated as $0.7 \times 10^{3}$ and $4.7 \times$ $10^{3}$, respectively. The polydispersity index (PDI) values were determined are quite wide, 4.81 and 6.50 for RI and UV measurements, respectively. The differences between RI and UV data would be attributed to heterogeneous distribution of components having aromatic moieties such as styrene unit sequence in the lower MW range. Overall, the SDR was found to be an oligomer with high PDI values with various main and side chain-length. consist of styrene/fumarate-isophthalate-glycol copolymers.

\section{Conclusion}

In this study, the viability of disintegrating and recycling robust large-scale multi-layered GFRP products using SHS was investigated. Four types of multi-layered GFRPs of different layer structures were employed as actual product samples. GFRPs were easily disintegrated and separated to each layer via SHS treatment at $350{ }^{\circ} \mathrm{C}$ under normal pressure. The separated layers were easily separated for subsequent recycling processes. During the SHS treatment, UP matrix was degraded partially and escaped via exhaust. Remaining SDR was attached on glass fiber surfaces as particulates. Subsequent thermal treatment at $500{ }^{\circ} \mathrm{C}$ and ultrasonication separated SDR from glass fiber surface, resulting in recovery of clear glass fibers. From FT-IR and ${ }^{1} \mathrm{H}-\mathrm{NMR}$ analyses of SDR, it was confirmed that the SDR was soluble in organic solvent and a low MW oligomer, consisting of phthalates, glycols, and styrene units due to partial cleavage of cured UP chains. Therefore, it was confirmed that the sequential disintegration of multi-layers and recycling system consisting of SHS, thermal, and ultrasonication treatments was successful in recovering clear glass fibers as well as soluble oligomers from actual large-scale multi-layered GFRP products.

\section{References}

[1] P.K. Mallick. Fiber-Reinforced Composites: Materials, Manufacturing, and Design. Third Edition. (CRC Press, Boca Raton, 2007).

[2] L.S. Lee, R. Jain, Clean Technol. Envir. 11:247-249 (2009).

[3] L.C. Hollaway, Constr. Build. Mater. 24:2419-2445 (2010).

[4] F.C. Robertson, Br. Polym. J. 20:417-429, (1988).

[5] A.P. Mouritz, E. Gellert, P. Burchill, K. Challis, Composite Structures 53:21-42, (2001).

[6] P. Beardmore, Compos. Struct. 5:163-176, (1986)

[7] G. Savage, Failure Anal. 17:92-115, (2010)

[8] M.C.S. Ribeira, A.C. Meira-Castro, F.G. Silva, J. Santos, J. P. Meixedo, A. Fiúza, M.L. Dinis, M.R. Alvim, Resour., Conserv. and Recycl. 104:417-426, (2015).

[9] N. Tanaka, Y. Tojo, T. Matsuto, J Mater Cycles Waste Manag 7:104-111, (2005).

[10] G. Grause, T. Mochizuki, T. Kameda, T. Yoshioka. J Mater Cycles Waste Manag 15:122-128, (2013).

[11] H. Shima, H. Takahashi, J. Mizuguchi, Mater. Trans. 52:1327-1329, (2011)

[12] T. Iwaya, S. Tokuno, M. Sasaki, M. Goto, K. Shibata, J. Mater. Sci. 43:2452-2456, (2008).

[13] T. Nakagawa, M. Goto, Polym. Degrad. Stab. 115:16-23, (2015)

[14] K. Maekawa, K. Shibata, M. Iwai, A. Endou. Hitachi Chemical Technical Report No. 42: 21-24, (2004)

[15] G. Oliveux, L.O. Dandy, G.A. Leeke, Prog. Mater. Sci. 72:61-99, (2015)

[16] J. Shi, L. Bao, Jpn. J. Appl. Phys. 50: 01AJ01-1-5, (2011).

[17] H. Nishida, N. Mouri, K. Oshima, T. Yamamoto, Reinf. Plas. 60:13-20, (2014).

[18] K. Hamada, K. Imai, H. Uematu, H. Kawakita Kochi Koshi Houkoku 21:8-12, (1990).

[19] Y.-J. Huang, J.-S. Leu, Polymer 34:295-304, (1993). [20] J.C. Yang, M.J. Jablonsk, J.W. Mays, Polymer 43:5125-5132, (2002).

[21] A.H. Kuptsov, G.N. Zhizhin, Handbook of Fourier Transform Raman and Infrared Spectra of Polymers, Volume 45 (Elsevier Science, Amsterdam, 1998). 